\title{
Perancangan dan Implementasi Network Monitoring Sistem Menggunakan Nagios dengan Email dan SMS Alert
}

\section{Design With Implementation of Network Monitoring System Using Nagios by Email and SMS Alert}

\author{
Hidra Amnur, Defni, Deddy Prayama \& Febrina Agustin \\ Jurusan Teknologi Informasi, Politeknik Negeri Padang \\ Telp. 0751-72590 Fax. 0751-72576
}

\section{ABSTRACT}

Network Monitoring System is a system which has a function to observe or monitor the computer network system is running. Network monitoring system can be implemented in real time in a computer network.

Development of network monitoring system using the local ip and web-based applications, where the construction of this network monitoring system using CentOS 6.4 operating system as the server.

Nagios is a network monitoring application based on open source that can be used according to user needs. To maximize the use of Nagios can use email and SMS as alerts.

Keywords : Network monitoring system, Nagios, Email alert, SMS alert.

\section{PENDAHULUAN}

Network Monitoring Sistem adalah sistem yang memiliki fungsi untuk mengamati atau memonitor sistem jaringan komputer yang sedang berjalan dan memungkinkan deteksi dini terjadinya kesalahan pada jaringan. Network Monitoring Sistem dilakukan dengan menggunakan sebuah komputer yang dijadikan sebagai server yang dihubungkan menggunakan jaringan lokal. Umumnya monitoring jaringan mengharuskan administrator untuk terus berada didepan layar agar mengetahui setiap perubahan yang terjadi hal ini kurang efisien. Untuk mengatasi permasalahan tersebut monitoring jaringan dapat dilakukan secara realtime menggunakan aplikasi Nagios. Nagios dapat memberi informasi tentang kondisi komponen jaringan secara realtime dengan mengirimkan pesan kepada administrator jaringan melalui email dan sms.

Tujuan dari penelitian adalah sebagai berikut :
- Bagaimana memanfaatkan sistem operasi CentOS 6.4 untuk membangun sebuah network monitoring sistem?

- Bagaimana membangun sebuah network monitoring sistem dengan memanfaatkan aplikasi nagios di sistem operasi CentOS 6.4 ?

- Bagaimana memaksimalkan pencapaian penggunaan nagios dengan menambahkan fitur email dan sms alert?

- Apa laporan kondisi host yang didapat setelah membangun network monitoring sistem menggunakan nagios?

- Apa manfaat menggunakan nagios untuk monitoring jaringan?

\section{METODOLOGI}

\section{Network Monitoring Sistem}

Menurut Henry Saptono [4]

Network Monitoring Sistem adalah sistem ekstra atau kumpulan sistem yang memiliki tugas mengamati/memonitor sistem-sistem terhadap kemungkinan terjadinya masalah-masalah pada sistem tersebut untuk dapat dideteksi secara dini. Suatu network monitoring sistem dapat 
secara periodik menghubungi suatu server untuk menjamin adanya respon dari server, jika tidak ada respon maka monitoring sistem kemudian mengirimkan pesan atau notifikasi ke administrator.

\section{Nagios}

Menurut Endah Mardiyani [5] Nagios adalah aplikasi monitoring yang dapat digunakan untuk monitoring sistem komputer, monitoring jaringan dan monitoring infrastruktur jaringan. Nagios berbasis open source yang dapat dijalankan pada sistem operasi Linux. Sistem monitoring Nagios memonitor seluruh infrastruktur IT untuk memastikan sistem, aplikasi, layanan, dan proses bisnis yang berfungsi dengan baik. Jika jaringan mengalami masalah, Nagios dapat langsung memberikan alert kepada teknisi jaringan sehingga memungkinkan teknisi untuk mengatasi masalah tersebut lebih awal.

Nagios diciptakan oleh Ethan Galstad. Nagios memiliki beragam fitur, antara lain memeriksa apakah server nyala/up, memberikan notifikasi apabila server/host mengalami masalah, memeriksa apakah servis yang digunakan masih berjalan, memberikan laporan melalui sms dan email tentang kondisi jaringan terbaru dan sebagainya. Berdasarkan fitur-fitur yang dimiliki nagios maka nagios sesuai untuk diimplementasikan di SMKN 1 Pasir Penyu.

\footnotetext{
Alert

Alert adalah notifkasi laporan yang dikirimkan nagios kepada kontak administrator. Alert dapat dikirim melalui SMS dan email. Alert dapat dikirim ketika nagios mendeteksi perubahan status pada suatu host atau servis, maka nagios akan memberitahukan melalui web interface dan $\log$ file serta mengirimkan notifikasi berupa email dan SMS kealamat administrator. Filter pesan merupakan aturan-aturan yang dibuat dalam konfigurasi agar aktivitas monitoring dan
}

notifikasi yang dikirim ke administrator yang diinginkan. [5]

Gambar 1. menunjukkan alur sistem notifikasi pada Nagios

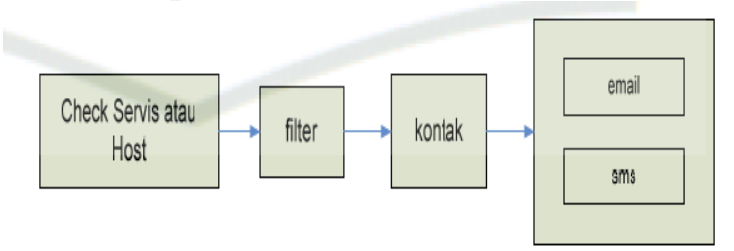

Gambar 1. Sistem notifikasi

\section{Centos}

CentOS (Community ENTerprise Operating System) merupakan Distro Linux yang cocok digunakan dalam skala Enterprise selain itu juga gratis. CentOS di buat dari source code Red Hat Enterprise (RHEL) yang dikembangkan oleh sebuah komunitas yang disebut CentOS Project. Software ini dirilis dibawah General Public License (GPL) yang selanjutnya dikembangkan oleh sebuah komunitas yang disebut CentOS Project. [6]

Keuntungan linux CentOS adalah open source, kompatibilitas, user friendly. CentOS tersedia secara gratis, dukungan teknis utamanya disediakan terhadap para pengguna melalui milis, forum berbasis web, ataupun chat. Proyek CentOS tidak berafiliasi dengan Red Hat. Untuk penggalangan dana, CentOS berbasis donasi dari para pengguna serta sponsor dari perusahaan-perusahaan yang menggunakannya. [6]

Berikut adalah tampilan awal installasi Linux CentOS 6.4.

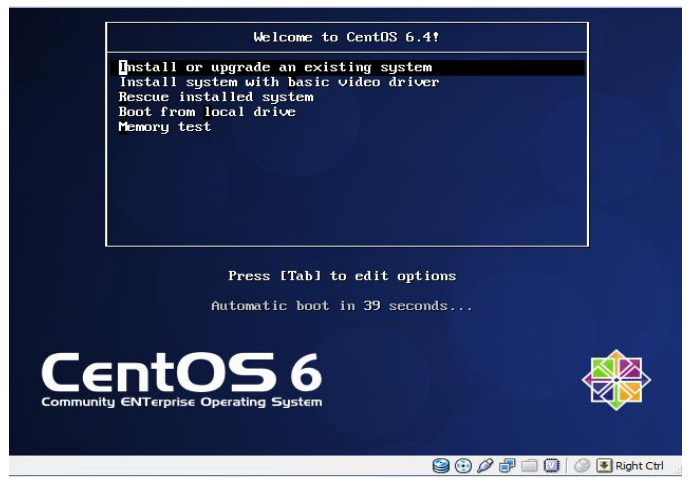

Gambar 2. Tampilan Awal Installasi CentOS 6.4 


\section{SendMail}

SendMail adalah sebuah server email standar yang satu paket (built-in) dengan sistem operasi Linux/Unix. Ada banyak versi SendMail yang sudah digunakan. Versi pertama adalah 8.8.5 dan diluncurkan tanggal 21 Januari 1997.

\section{Rancangan Sistem}

Arsitektur sistem terdiri dari perangkat yang digunakan, langkah kerja sistem monitoring jaringan yang dibuat dan sistematika pelaporan notifikasi keadaan jaringan berupa SMS dan Email yang dikirimkan kepada admin.

Gambar 3. menunjukkan arsitektur sistem yang akan dibuat,

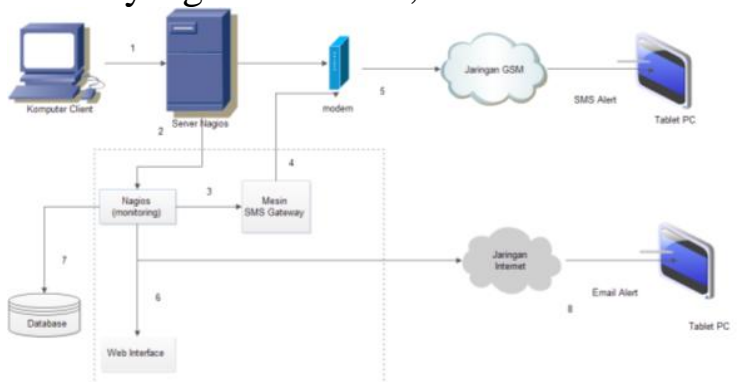

Gambar 3. Arsitektur Sistem

Berikut penjelasan arsitektur sistem di atas :

1. Server ( yang telah diinstal nagios ) mendeteksi perubahan status pada komputer client.

2. Nagios memproses apakah perubahan status pada client perlu diberitahukan pada admin atau tidak.

3. Notifikasi melalui sms akan dikirim oleh mesin SMS gateway.

4. Mesin SMS gateway meneruskan pesan ke modem.

5. Modem mengirimkan pesan ke ponsel admin melalui jaringan GSM.

6. Perubahan keadaan pada jaringan akan ditampilkan pada web interface nagios.

7. Selain ditampilkan pada web, data-data yang dihasilkan juga akan tersimpan dalam database.

8. Notifikasi dikirim melalui email ke alamat admin melalui jaringan internet.

HASIL DAN PEMBAHASAN

\section{Implementasi}

Implementasi dilaksanakan setelah tahap perancangan hardware dan software yang akan digunakan. Secara garis besar langkah-langkah pelaksanaan implementasi yang akan dilakukan adalah sebagai berikut

1. Meng-install CentOS 6.4 Server pada PC Server yang akan difungsikan sebagai server nagios.

2. Mengkonfigurasi IP Address dan layanan SSH pada server.

3. Meng-install LAMP server (Linux, Apache, Mysql, PHP).

4. Meng-install dan mengkonfigurasi repository epel.

5. Meng-install dan mengkonfigurasi Nagios 3.5.1 .

6. Mengkonfigurasi Email Alert Nagios

7. Mengkonfigurasi SMS Alert Nagios

\section{Instalasi CentOS 6.4 pada PC Server}

PC server yang digunakan sebagai server nagios menggunakan sistem operasi CentOS server 6.4.

a. Setting IP Address dan Konfigurasi SSH (Secure Shell)

b. Instalasi LAMP server (Linux, Apache, Mysql, PHP)

c. Setelah melakukan instalasi LAMP, kemudian melakukan restart terhadap servis httpd yang telah ditambahkan paket mysql dan php. Hal ini dilakukan untuk mengaktifkan konfigurasi yang telah ditambahkan. Berikut perintah restart httpd.

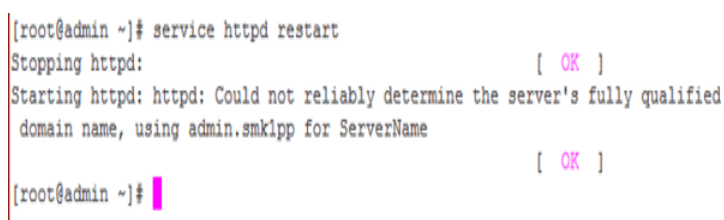

Gambar 4. Perintah restart servis httpd

d. Untuk memanfaatkan mysql dan php secara efektif, maka mysql dan php harus dihubungkan. Menyambungkan php dan mysql menggunakan perintah instalasi "yum install mysql-php". Gambar 5. menunjukkan perintah menyambungkan php dan mysql. 


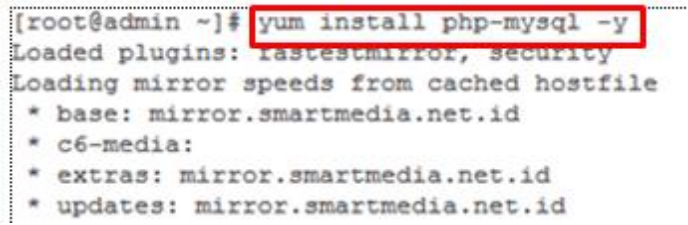

Gambar 5. Perintah menyambungkan php dan mysql

e. Berikut merupakan indikasi proses instalasi selesai, seperti pada gambar 6 .

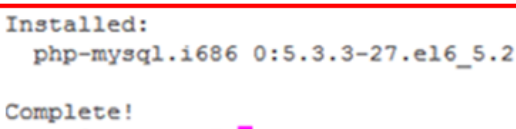

Gambar 6. Proses instalasi mysql-php

f. Meng-install phpmyadmin untuk melengkapi instalasi LAMP. Phpmyadmin merupakan tool antarmuka web gratis yang digunakan untuk mengelola database. Berikut proses instalasi phpmyadmin pada gambar 7.

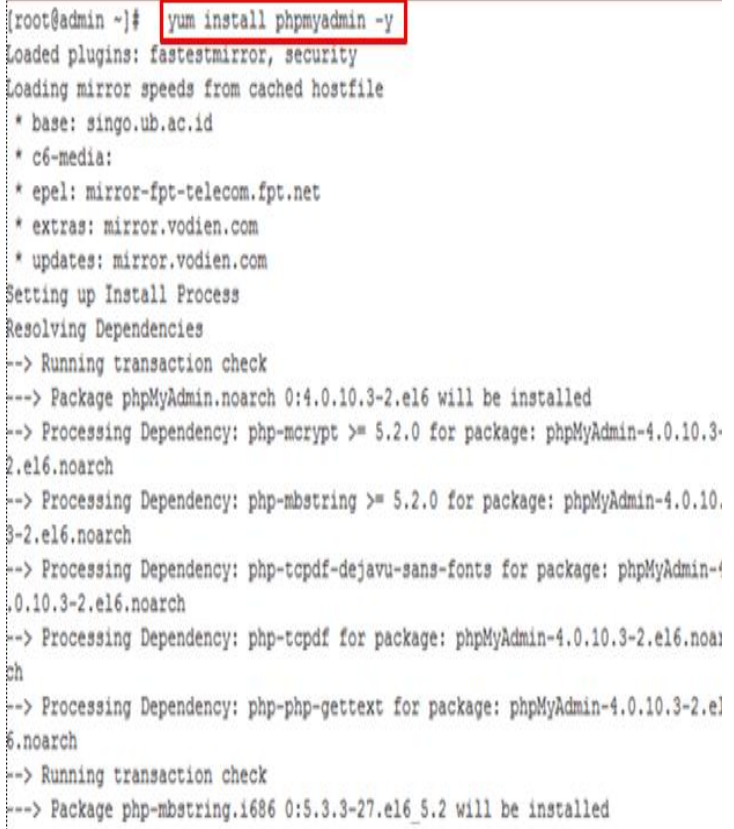

Gambar 7. Perintah instalasi phpmyadmin

g. Gambar 8 . berikut menunjukkan tampilan instalasi phpmyadmin setelah terinstall.

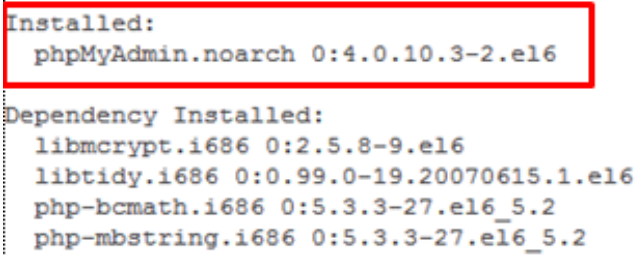

Gambar 8. Proses instalasi myphpadmin

h. Mengedit file "phpmyadmin.conf" yang terdapat pada direktori letc/httpd/conf.d/phpmyadmin.conf dengan menjadikan isi sebagai komentar dengan menggunakan tanda \# seperti gambar 9.

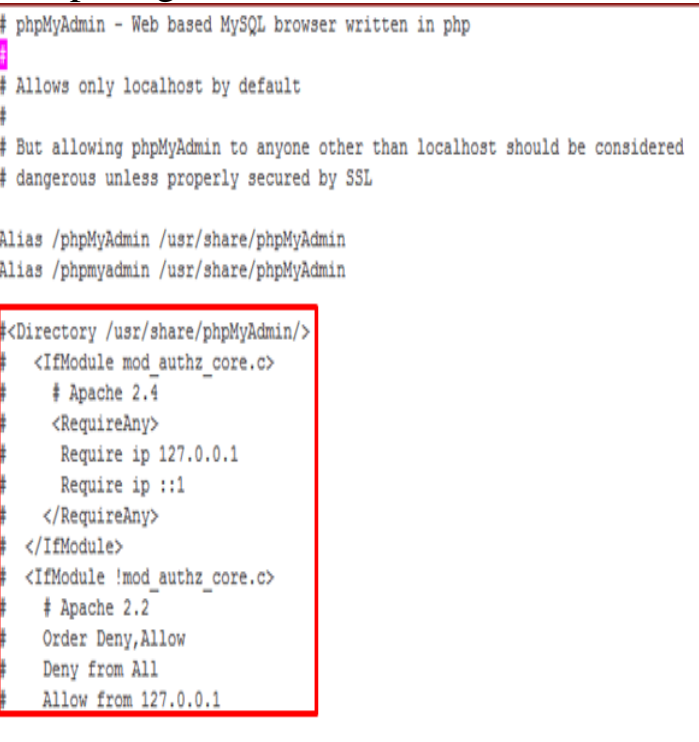

Gambar 9. Mengedit file phpmyadmin.conf

i. Selanjutnya me-restart servis httpd untuk menjalankan perubahan yang telah dilakukan.

[rootfadmin phplyadmin] \& service httpd regtart

Stopping httpd: $\quad$ ( OR |

Starting httpd: httpd: Could not reliably determine the server's fully qualified domain name, using admin. smikipp for ServerName

[rootQadmin phplyadmin]

Gambar 10. Perintah restart httpd

j. Instalasi Repository EPEL

Nagios tidak terdapat di repository CentOS, sehingga untuk menginstal nagios diharuskan untuk menambah repository epel yang memiliki source code nagios.

a) Meng-install repository epel dengan menggunakan perintah 


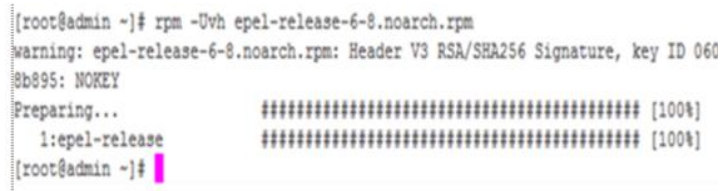

Gambar 11. Proses instalasi respositori epel

b) Melihat repository epel yang telah terinstall menggunakan perintah

repo name "yum repolist".

Centos-6 - Base

CentoS-6 - Media

Extra Packages for Enterprise Linux 6 - 1386

centos-6 - Extras

CentOS-6 - Updates

Gambar 11. Paket EPEL yang telah terinstall

Berikut menu yang terdapat pada nagios:

1. Map

Map berisi peta host yang terhubung ke server nagios. Dari hasil monitoring terlihat 6 buah host sedang dalam kondisi down/mati dan 2 host dalam keadaan up/nyala. Seluruh host terhubung ke nagios proses seperti tampak pada gambar 12.

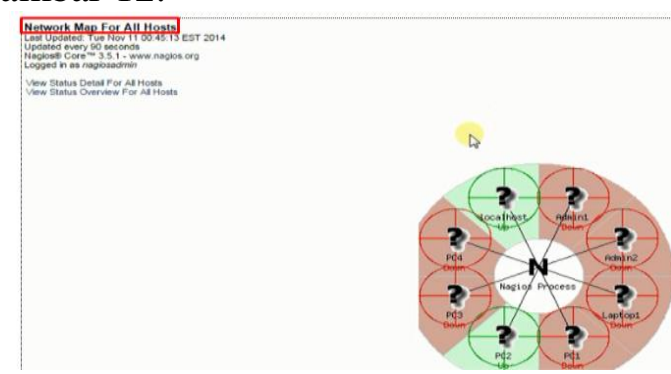

Gambar 12. Map

PC2 dalam keadaan up atau nyala. Ketika ditunjuk menggunakan pointer tampak rincian status PC2. Isi data status dari PC2 yang ditunjuk pointer adalah nama localhost, ip address 192.168.1.28, informasi status "PING OK", pengecekan status dan perubahan status terakhir pada 11 november 2014. Data-data perubahan status dari klien monitoring tersimpan dalam file $\log$ nagios. Status dari PC2 dapat dilihat pada gambar 13 .

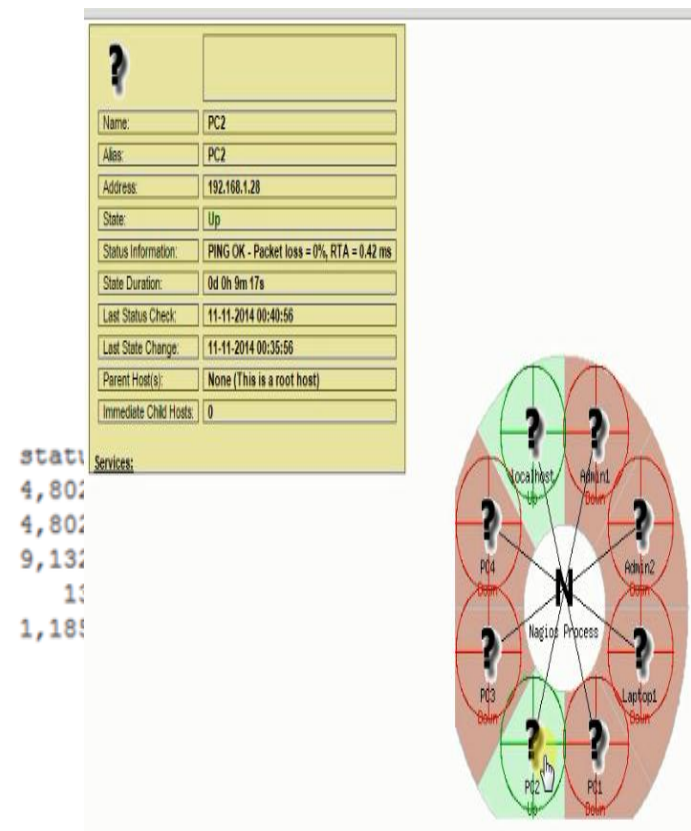

Gambar 13. Status PC2

\section{Hosts}

Berdasarkan gambar 13. tampak host admin1, admin2, laptop1, PC1, PC 3 dan PC 4 sedang dalam keadaan down. PC 2 sedang dalam keadaan perubahan status dan status terbaru adalah up. Localhost dalam keadaan up. Gambar 14. menunjukkan kondisi jaringan yang sedang terjadi. Berdasarkan data update terakhir monitoring dilakukan pada tanggal 11 november 2014. Durasi montoring adalah 30 menit. Terdapat jumlah host dan status yang terhubung ke server nagios yang dapat dilihat pada bagian atas report . Terdapat status informasi host hasil monitoring host yang telah dilakukan.

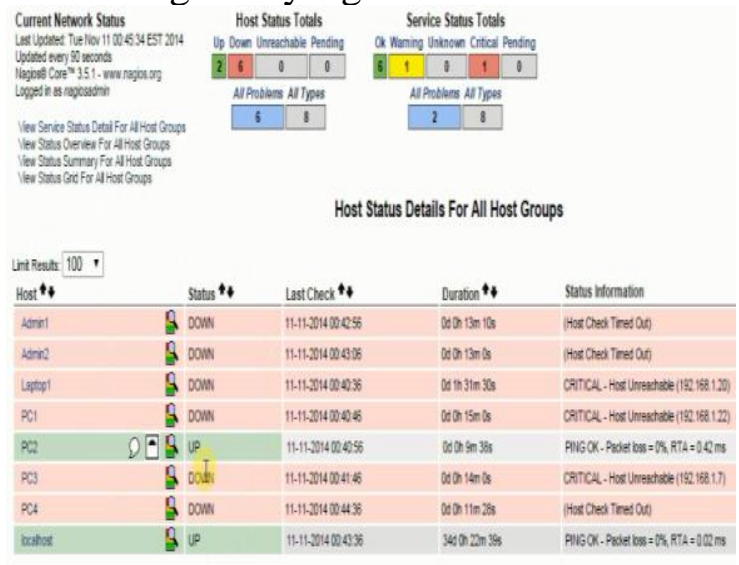

Gambar 14. Kondisi jaringan yang terjadi

3. Group 
Menampilkan status grup yang terdapat pada nagios. Grup yang terdapat pada nagios hasil monitoring adalah localhost. Semua host tergabung dalam grup localhost. Berikut status grup yang terdapat pada sistem monitoring. Gambar 15. menunjukkan servis grup yang terdapat pada Nagios.

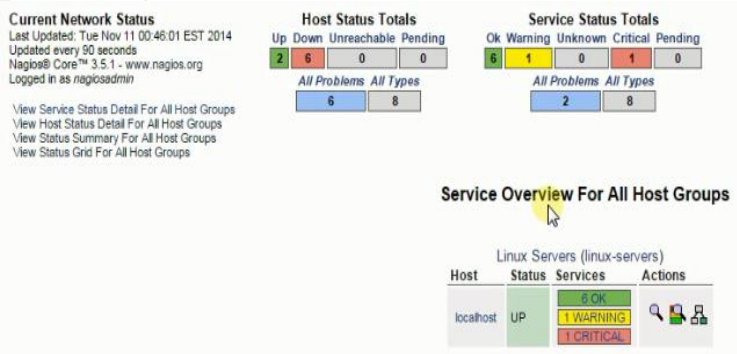

Gambar 15. Group

4. Availability report ( laporan ketersediaan )

Pada nagios, pengguna dapat membuat laporan ketersediaan host yang dibuat perminggu atau sesuai keinginan pengguna. Availability report berisi presentase kondisi host yang di monitoring. Berikut langkah pembuatan report availability:

a. Memilih jenis report yang akan dibuat sebagai availability report, admin memilih membuat hostgroup report untuk dibuat sebagai report .

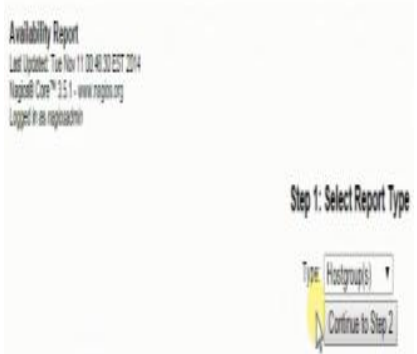

Gambar 16. Select Report Type

b. Memilih host yang akan dibuat report nya. Pada pilihan "select host". Admin memilih semua host untuk ditampilkan availability report -nya.

Maka data yang akan ditampilkan dalam report akan berisi data seluruh host yang telah di monitoring.
AvalibollityRepoit

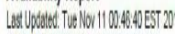

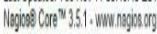

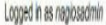

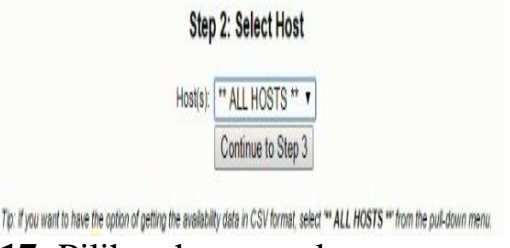

Gambar 17. Pilihan host untuk report

c. Kemudian memilih jenis report sesuai keinginan admin. Admin dapat menyesuaikan data report sesuai kebutuhan admin. Admin dapat menyesuaikan periode report yang ingin dibuat, penggunaan inisial status dan sebagainya.
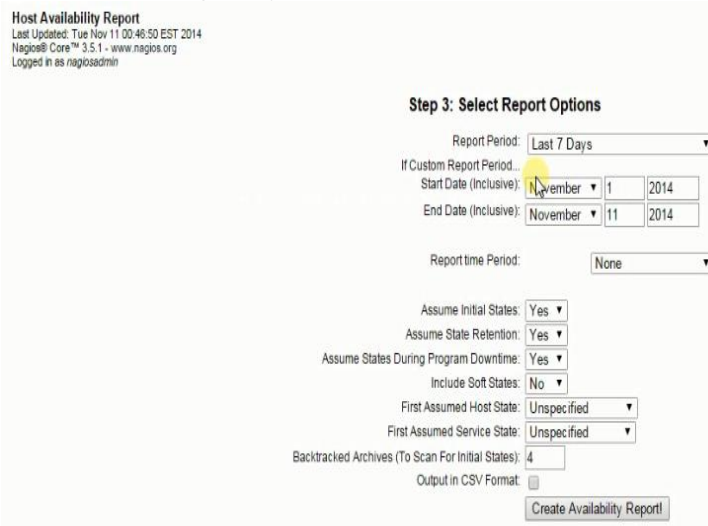

Gambar 18. Report Option

d. Tampilan availability report untuk semua host. Terdapat persentasi kondisi host yang di monitoring. Peresentasi tersebut meliput time up, time down, time unreachable dan time down.

All Hosts
$\begin{aligned} & \text { 11-04-2014 00:46.57 to } 11-11-201400.46: 57 \\ & \text { Duration. } 70 \text { on on os }\end{aligned}$

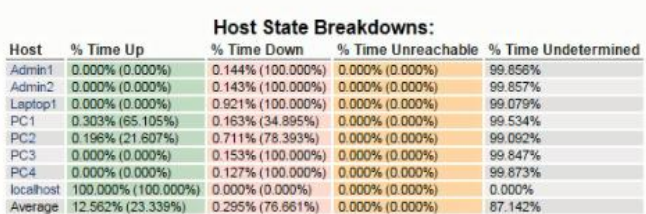

Gambar 19. Availability report semua host

\section{Host and service state trends}

Admin dapat membuat report yang berisi host dan servis yang menjadi tren 
beberapa waktu. Berikut langkah-langkah pembuatan "Host and service state trends":

a. Memilih tipe report yang akan dibuat. Tipe report meliputi report untuk host atau report untuk servis. Gambar 20. menunjukkan report yang telah dipilih admin.

Host and Service State Trends

Ins Updated Tue Nor 11 00.47.12 EST 201

Nagiose Core $" 3.51 \cdot$ - www. ngage org

Step 1: Select Report Type

Type: Host ,

Continue to Step 2

Gambar 20. Memilih jenis report

b. Memilih salah satu host yang akan dibuat report . Admin dapat memilih host yang akan dibuat report. Host yang dibuat report adalah PC2.

Host and Service State Trends

Los Updeted. Tue Nov 11 00.47.25 EST 201

Nogiose Core" " 3.5.1 - www nagios org

Logeet nas nogposodinin

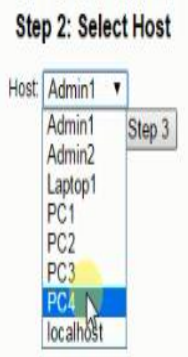

Gambar 21. Gambar memilih host

c. Gambar 22. menunjukkan tampilan report tren host PC2. Terlihat pada tanggal 10 november PC2 mengalami kondisi down dan pada tanggal 11 november PC 2 mengalami kondisi $U P$. Telah terjadi perubahan status dari PC2 antara tanggal 10 november dan 11 november 2014.

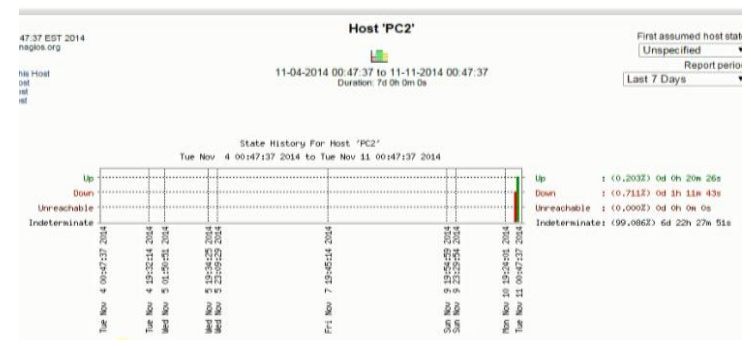

Gambar 22. Tren report PC2
6. Alert

Alert merupakan pemberitahuan informasi status yang terjadi pada klien nagios dalam sebuah jaringan. Alert dapat berupa tampilan interface web, SMS dan Email.

a. Alert history

Nagios menyimpan history dari alert yang telah berjalan di nagios. Berikut beberapa history alert yang terekam di nagios. Gambar 5.5.23 menunjukkan alert history. Tampak pada alert history kebanyakan status host dalam keadaan Down. Terdapat sedikit informasi kondisi host yang down meliputi critical dan host unreachable.
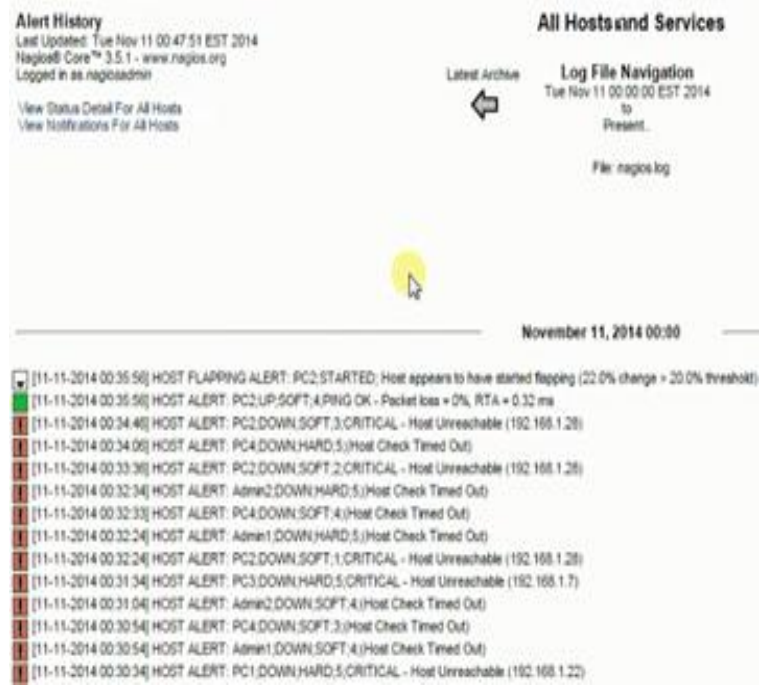

Gambar 23. Alert History

\section{b. Alert Summary Report}

Berisi ringkasan laporan alert yang telah terjadi. Alert summary report melaporkan kondisi state dan informasiinformasi yang berhubungan dengan monitoring yang telah dilakukan. Berikut langkah-langkah membuat Alert Summary Report .

1) Menyesuaikan alert report yang akan dibuat sesuai kebutuhan admin, lalu mengklik "create summary report ". Admin dapat memilih variable kondisi yang ingin dilaporkan seperti 25 hard alert terakhir yang telah terjadi dan dapat menambahkan penyesuaian dengan menggunakan "costum report option”. Pada costum report option 
dapat ditentukan kriteria-kriteria yang ingin dimasukkan kedalam report.

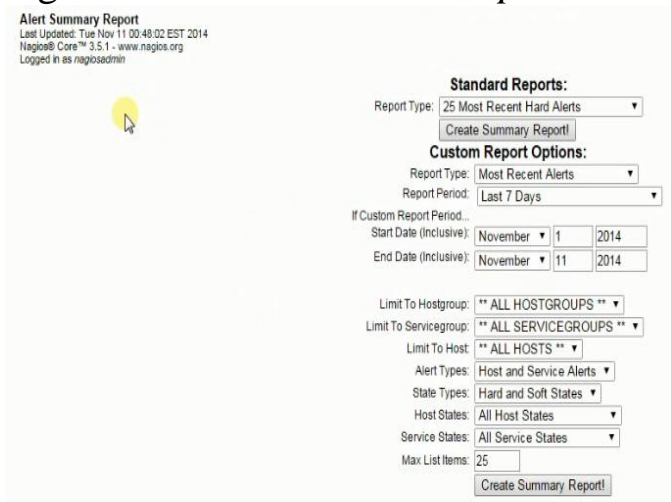

Gambar 24. Form pembuatan report

2) Berikut hasil pembuatan report yang telah dibuat.

\begin{tabular}{|c|c|c|c|c|c|c|c|}
\hline 2014 & & & 11.04 & $\begin{array}{l}\text { Most Rec } \\
400: 48.091 \\
\text { Duration: }\end{array}$ & $\begin{array}{l}\text { alerts } \\
11-11-2014 \mathrm{C} \\
\text { Oh Om Os }\end{array}$ & $00.48: 09$ & $\begin{array}{l}\text { Aler } \\
\text { Stat } \\
\text { Hos } \\
\text { Servica }\end{array}$ \\
\hline \multirow[b]{2}{*}{ Time } & \multicolumn{6}{|c|}{ Displajing al 9 matching alerts } & \\
\hline & Alert Type & Host & Service & State & State Type & Intormation & \\
\hline $11-11-20140034406$ & Host Alert & PC4 & NA & DOWN & HARD & (Hos Cheek Tmed Out) & \\
\hline 11.11 .2014003234 & Hos Alert & Aotmn2 & N/A & DOWN & HARD & (Host Check Tmed Out) & \\
\hline $11-11-20140032224$ & Hos Alert & Adomin & NAA & DOWN & HARD & (Host Cheek Tmed Out) & \\
\hline $11-11-20140031: 34$ & Hos Aleert & PC3 & NAA & DONN & HARD & CRTICAL - Host Unreachable (192.168.1.7) & \\
\hline $11-11 \cdot 2014003030.34$ & Hos Alert & PCI & NAA & DOWN & HARD & CRTTCAL - Hot Unreechable (192.168.122) & \\
\hline $11-11-20140027.11$ & Hos ât & PC2 & N/A & UP & HARD & PING OK- Pacter loss $=0 \%, R T A=0.32 \mathrm{~ms}$ & \\
\hline 11-10-2014 23:15:28 & Hos Alert & PC2 & NAA & DOWN & HARD & CRTICAL - Host Unreachable (192.168.122) & \\
\hline $11-10-201423: 1404$ & Hos Alett & Lastopl & NA & DOWN & HARD & CRTICAL - Host Unreechable (192168.1.20) & \\
\hline $11.09-201421: 18.09$ & Service Alert & besalhost & Total Proces s a s a & 5 CRIICA. & HARD & Return cose of 127 i s out of bounds. plugin $m$ & e missing] \\
\hline
\end{tabular}

Gambar 25. Most recent alert

Dari hasil pembuatan report dapat dilihat bahwa pembuatan report pada tanggal 11 november 2014. Alert type host atau service alert. Alert host terjadi pada host yang bersistem operasi windows sedangkan sevice alert untuk PC yang bersistem operasi linux. Terlihat pada report tersebut menunjukkan status up atau down.

\section{Contact Notifications}

Contact notifications dibuat melalui email dan sms. Sesuai dengan judul tugas akhir yang menyangkut Email dan SMS alert. Terdapat notification command untuk notifikasi melalui email dan alert yang telah berjalan. Tampak setiap perubahan status host telah dilaporkan melalui email dan sms yang telah dikonfigurasi pada nagios menggunakan smtp sendmail untuk email alert dan gammu untuk sms alert. Terlihat email dan sms terkirim pada kontak yang telah terdata pada nagios.

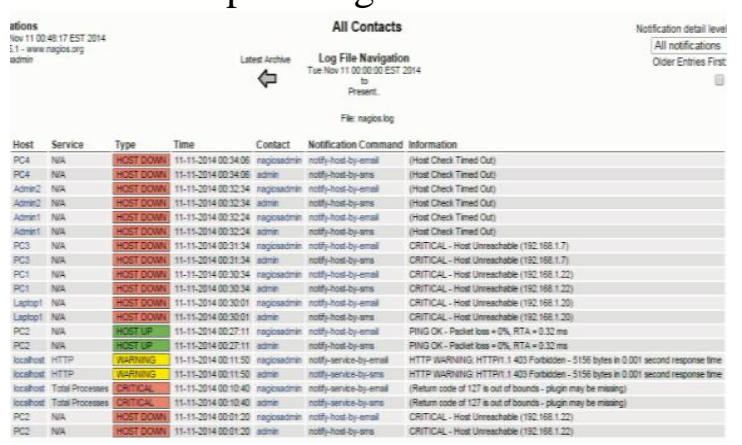

Gambar 26. Contact Notifications

\section{Pengujian Email dan SMS alert}

Pengujian berupa hasil email dan sms yang telah dikirimkan oleh server nagios kepada admin yang telah dikonfigurasi sebelumnya.

1) Email alert

Berikut hasil dari email notifikasi yang dikirim oleh sever nagios. Email berisi sebuah permasalahan dimana status dari host dengan alamat IP Address 192.168.1.22 down.

Gambar 5.5.28 menunjukkan email yang telah dikirim server nagios. Client dengan ip address 192.168.1.22 mengalami kondisi down dan host unreachble.

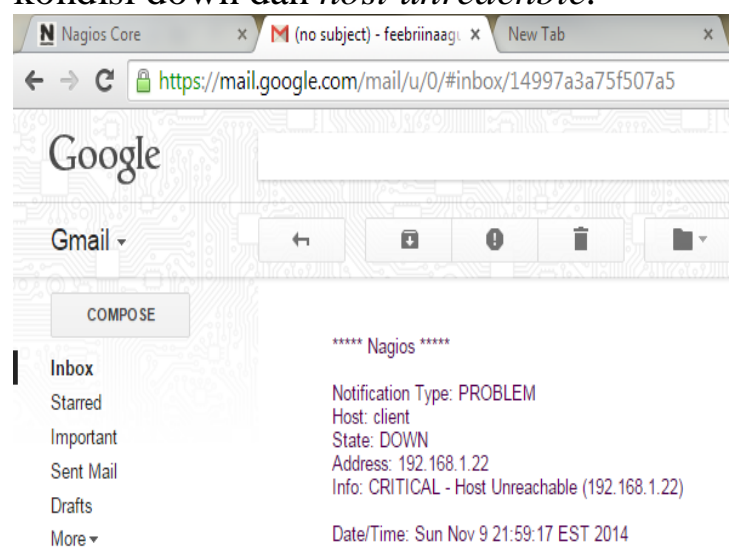

Gambar 27. Email Alert

\section{2) SSMS Alert}

SMS dikirim oleh server nagios melalui jaringan GSM yang dimiliki kartu sim yang terdapat pada modem . Kartu SIM yang digunakan adalah XL dengan nomor telepon +6281993004410 . Terdapat data yang sama antara email dan sms alert 
yaitu host dengan alamat 192.168.1.22 mengalami kondisi down.

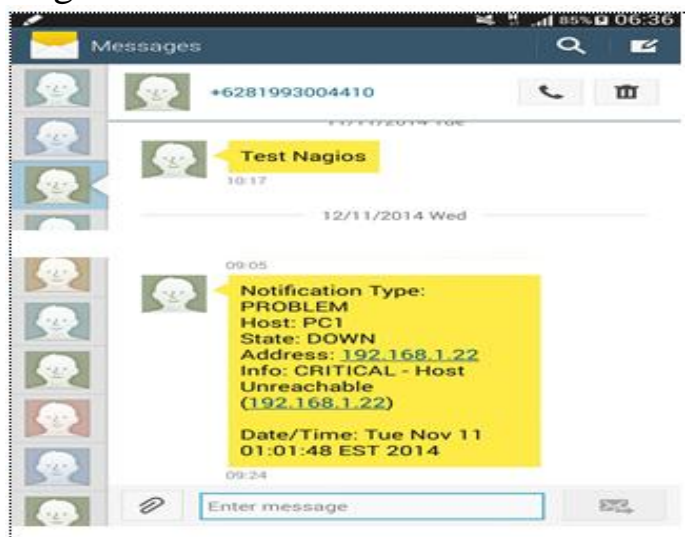

Gambar 28. SMS Alert

\section{SIMPULAN}

Penelitian telah dilakukan membahas tentang monitoring host yang meliputi perancangan, implementasi dan pengujian, sehingga diperoleh beberapa kesimpulan di antaranya sebagai berikut :

1. Monitoring dilakukan untuk melihat kondisi UP atau Down dari sebuah host.

2. Sistem monitoring dapat mendeteksi perubahan status host yang terjadi.

3. Hasil monitoring dapat diakses menggunakan web browser dengan memasukkan ip server .

4. Hasil monitoring dapat dilaporkan sebagai sebuah report yang berdasarkan servis atau host.

5. Hasil monitoring juga dapat memberi gambaran tren yang sedang terjadi terhadap host.

6. Sistem monitoring dapat dilengkapi menggunakan Email dan SMS alert untuk mempermudah admin agar mendapatkan informasi kondisi host dimana saja.

\section{SARAN}

Adapun sarana adalah sebagai berikut :

1. Untuk hasil maksimal dalam penerapan monitoring ini sebaiknya digunakan ip publik untuk server agar bisa diakses dari manapun juga.
2. Untuk hasil yang lebih akurat dan maksimal, sebaiknya server nagios selalu aktif.

3. Sebaiknya dikembangkan lagi penggunaan nagios sebagai monitoring server.

\section{DAFTAR PUSTAKA}

Fatahna, Muhammad An'im (2011) : EBook CentOS Network Administra

Nugroho, Bunafit (2005) : Instalasi dan Konfigurasi Jaringan Windows dan Linux. Yogyakarta : Andi

Muhammad Linto Herlambang (2009) : Membangun Jaringan Koneksi. Yogjakarta: Andi

Mardiyani, Endah (2011) : Jurnal "Implementasi Nagios untuk Merancang Sistem Monitoring Client Jaringan Komputer Menggunakan SMS dan Email"

Sutono (2010) : Perangkat Keras Komputer dan Tools Pendukungnya. Bandung : Modula

Saptono, Henry. 2008. Jurnal Network Monitoring System dengan Nagios 